\title{
New Orthogonal Binary Sequences Using Quotient Rings ZInZ Where $n$ Is a Multiple of Some Prime Numbers
}

\author{
Ahmad Hamza Al Cheikha \\ Department of Mathematical Science, College of Arts-science and Education, Ahlia University, Manama, Bahrain \\ Email address: \\ alcheikhaa@yahoo.com
}

To cite this article:

Ahmad Hamza Al Cheikha. New Orthogonal Binary Sequences Using Quotient Rings Z/nZ Where $n$ Is a Multiple of Some Prime Numbers. International Journal of Wireless Communications and Mobile Computing. Vol. 8, No. 1, 2020, pp. 9-17. doi: 10.11648/j.wcmc.20200801.12

Received: July 17, 2020; Accepted: September 27, 2020; Published: October 14, 2020

\begin{abstract}
Orthogonal Sequences (as M-Sequences, Walsh Sequences,...) are used widely at the forward links of communication channels to mix the information on connecting to and at the backward links of these channels to sift through this information is transmitted to reach the receivers this information in a correct form, especially in the pilot channels, the Sync channels, and the Traffic channel. This research is useful to generate new sets of orthogonal sequences (with the bigger lengths and the bigger minimum distance that assists to increase secrecy of these information and increase the possibility of correcting mistakes resulting in the channels of communication) from quotient rings $\mathrm{Z} / n \mathrm{Z}$, where $\mathrm{Z}$ is the integers and $n$ is not of the form $p^{m \text {, }}$ where $p$ is prime, replacing each event number by zero and each odd number by one, also, the increase in the natural number does not necessarily lead to an increase in the size of the biggest orthogonal set in the corresponding quotient ring. The length of any sequence in a biggest orthogonal set in the quotient ring $\mathrm{Z} / n \mathrm{Z}$ is $n$ and the minimum distance is between (n-3)/2 and (n-1)/2 and the sequences can be used as keywords or passwords for secret messages.
\end{abstract}

Keywords: Walsh Sequences, M-sequences, Additive Group, Coefficient of Correlation, Orthogonal Sequences, Quotient Ring

\section{Introduction}

Shannon's classic articles, 1948-1949, were followed by many research papers on the question of finding successful ways to encode a successful encoding of the media to allow it to be transmitted correctly through jammed channels. [1]

The main obstacle to encoding and decoding is the complexity of decoding and decoding. For this reason, efforts have been made to design cryptographic and decoding methods in an easy way. The works of Hocquenghem in 1959, Reed Solomon 1960, Chaudhuri and Bose in 1960, $\mathrm{BCH}$ codes or Bose-Chaudhuri-Hocquenghem codes and others as Goppa, and Petrson 1961 were a new starting point for solving this issue. [2-8]

In all stages of encoding and decoding the orthogonal sequences play the main role in these processes $n$ all stages of encoding and decoding, the orthogonal sequences play the main role in these processes, including: the sequences with maximum period M-Sequences, the Walsh sequences, the Reed-Solomon sequences, and the other. [9-12]

In $2018 \mathrm{Al}$ Cheikha A. H. publish an article "Generating
New Binary Sequences Using Quotient Rings $Z / p^{m} Z$ "and current article is extending to this article. [13]

Orthogonal Sequences are used widely at the forward links of communication channels to sift through this information is transmitted to reach the receivers this information in a correct form, especially in the pilot channels, the Sync channels, and the Traffic channel. [14-17]

\section{Research Method and Material}

Definition 1. The complement of the binary vector $X=\left(x_{1}, x_{2}, \ldots, x_{n}\right), x_{i} \in F_{2}\{0,1\} \quad$ is the vector $\bar{X}=\left(\overline{x_{1}}, \overline{x_{2}}, \ldots, \overline{x_{n}}\right)$, where:

$$
\overline{x_{i}}=\left\{\begin{array}{lll}
1 & \text { if } & x_{i}=0 \\
0 & \text { if } & x_{i}=1
\end{array}\right.
$$

Definition 2. (Euler function $\varphi$ ). $\varphi(n)$ is the number of the natural numbers that are relatively prime with $n$.

Definition 3. Suppose $x=\left(x_{0}, x_{1}, \ldots, x_{n-1}\right)$ and 
$y=\left(y_{0}, y_{1}, \ldots, y_{n-1}\right)$ are binary vectors of length $n$ on $G F(2)=\{0,1\}$. The coefficient of correlations function of $x$ and $y$, denoted by $R_{x, y}$ is:

$$
R_{x, y}=\sum_{i=0}^{n-1}(-1)^{x_{i}+y_{i}}
$$

Where $x_{i}+y_{i}$ is computed $\bmod 2$. It is equal to the number of agreements components minus the number of disagreements corresponding to components or if $x_{i}, y_{i} \in\{1,-1\}$ (usually, replacing in binary vectors $x$ and $y$ each " 1 " by " -1 " and each " 0 " by " 1 ") then

$$
G=\left\{X ; X=\left(x_{0}, x_{1}, \ldots, x_{n-1}\right), x_{i} \in F_{2}=\{0,1\}, i=0,1, \ldots, n-1\right\}
$$

Let's $1^{*}=-1$ and $0^{*}=1$, The set $G$ is said to be orthogonal if the following two conditions are Satisfied:

$$
\text { 1. } \forall X \in G, \sum_{i=0}^{n-1} x_{i}^{*} \in\{-1,0,1\}, \text { or }\left|R_{x, 0}\right| \in\{-1,0,1\} \text {. }
$$

Or; the difference between the number of " $0 . s "$ and the number of " $1 . s "$ is at most one.

$$
\text { 2. } \forall X, Y \in G(X \neq Y), \sum_{i=0}^{n-1} x_{i}^{*} y_{i}^{*} \in\{-1,0,1\} \text { or }\left|R_{x, y}\right| \in\{-1,0,1\} \text {. }
$$

That is, the absolute value of "the number of agreements minus the number of disagreements" is at most equal to one. [3, 7],

[9-14]

Theorem 1.

$\varphi\left(p^{s}\right)=p^{s}\left(1-\frac{1}{p}\right)$, where $p$ is prime.

$\varphi(m . n)=\varphi(m) . \varphi(n)$, if $\operatorname{gcd}(m, n)=1$.

$\varphi(m)=m \prod_{p \mid m}\left(1-\frac{1}{p}\right), p$ is prime or if $n=\prod_{i=1}^{k} p_{i}^{m_{i}}$ then $\varphi(n)=\prod_{i=1}^{k} p_{i}^{m_{i}-1}\left(p_{i}-1\right)$.

$\sum_{d \mid m} \varphi(d)=m$, where $d$ is all divisors of $m$ including 1 and $m .[11,12,16]$

Result. if $n$ larger than 1 to $\varphi(n)$ is even except $\varphi(2)=1$.

\section{Results and Discussion}

In this study we restrict our self $n \neq p^{m}, p$ is prime.

\section{1. $n$ Is Odd}

The best method for getting the binary representation of the multiplication table of the quotient $\operatorname{ring} Z /(n Z)$, where $Z$ is the integers and $n$ is natural number larger than 1 , is replacing each event number by " 0 " and replacing each odd number by " 1 ', by this way each row with the index $i$ relatively prime with $n$ contains $(n+1) / 2$ of ' $0 . s$ ' and $(n-1) / 2$ of " $1 . s$ " and the row $r i$ is the conjugate of $r(n-i)$ that is the entries in $r i+r(n-i)$ are equal to zero by $\bmod n$.

We searching between these rows about a comfortable subset of rows which with the null row form additional subgroups achieve the number of " $0 . \mathrm{s}$ " and the number of "1.s" or orthogonal conditions in the vector space $2^{n}$, where the addition is performed by $\bmod 2$.

\subsection{1. $n=(3)(5)=15$}

\begin{tabular}{|c|c|c|c|c|c|c|c|c|c|c|c|c|c|c|c|c|}
\hline & $*$ & 0 & 1 & 2 & 3 & 4 & 5 & 6 & 7 & 8 & 9 & 10 & 11 & 12 & 13 & 14 \\
\hline$r 0$ & 0 & 0 & 0 & 0 & 0 & 0 & 0 & 0 & 0 & 0 & 0 & 0 & 0 & 0 & 0 & 0 \\
\hline$r 1$ & 1 & 0 & 1 & 2 & 3 & 4 & 5 & 6 & 7 & 8 & 9 & 10 & 11 & 12 & 13 & 14 \\
\hline$r 2$ & 2 & 0 & 2 & 4 & 6 & 8 & 10 & 12 & 14 & 1 & 3 & 5 & 7 & 9 & 11 & 13 \\
\hline$r 3$ & 3 & 0 & 3 & 6 & 9 & 12 & 0 & 3 & 6 & 9 & 12 & 0 & 3 & 6 & 9 & 12 \\
\hline$r 4$ & 4 & 0 & 4 & 8 & 12 & 1 & 5 & 9 & 13 & 2 & 6 & 10 & 14 & 3 & 7 & 11 \\
\hline$r 5$ & 5 & 0 & 5 & 10 & 0 & 5 & 10 & 0 & 5 & 10 & 0 & 5 & 10 & 0 & 5 & 10 \\
\hline$r 6$ & 6 & 0 & 6 & 12 & 3 & 9 & 0 & 6 & 12 & 3 & 9 & 0 & 6 & 12 & 3 & 9 \\
\hline
\end{tabular}

For the quotient ring $Z / 15 Z$ the following table 1 showing the multiple in the ring $Z / 15 Z$ :

Table 1. Multiplication Table of $Z / 15 Z$. 


\begin{tabular}{|c|c|c|c|c|c|c|c|c|c|c|c|c|c|c|c|c|}
\hline & $*$ & 0 & 1 & 2 & 3 & 4 & 5 & 6 & 7 & 8 & 9 & 10 & 11 & 12 & 13 & 14 \\
\hline$r 7$ & 7 & 0 & 7 & 14 & 6 & 13 & 5 & 12 & 4 & 11 & 3 & 10 & 2 & 9 & 1 & 8 \\
\hline$r 8$ & 8 & 0 & 8 & 1 & 9 & 2 & 10 & 3 & 11 & 4 & 12 & 5 & 13 & 6 & 14 & 7 \\
\hline$r 9$ & 9 & 0 & 9 & 3 & 12 & 6 & 0 & 9 & 3 & 12 & 6 & 0 & 9 & 3 & 12 & 6 \\
\hline$r 10$ & 10 & 0 & 10 & 5 & 0 & 10 & 5 & 0 & 10 & 5 & 0 & 10 & 5 & 0 & 10 & 5 \\
\hline$r 11$ & 11 & 0 & 11 & 7 & 3 & 14 & 10 & 6 & 2 & 13 & 9 & 5 & 1 & 12 & 8 & 4 \\
\hline$r 12$ & 12 & 0 & 12 & 9 & 6 & 3 & 0 & 12 & 9 & 6 & 3 & 0 & 12 & 9 & 6 & 3 \\
\hline$r 13$ & 13 & 0 & 13 & 11 & 9 & 7 & 5 & 3 & 1 & 14 & 12 & 10 & 8 & 6 & 4 & 2 \\
\hline$r 14$ & 14 & 0 & 14 & 13 & 12 & 11 & 10 & 9 & 8 & 7 & 6 & 5 & 4 & 3 & 2 & 1 \\
\hline
\end{tabular}

Where "*" is the multiplication on $Z / 15 Z$ and we can see that $1,2,4,7,8,11,13,14$ are relatively prime with 15 and $r 1+r 14=r 2+r 13=r 4+r 11=[00 \ldots 0]_{15}$.

Table 2 showing the binary representation of table 1 , when in table 1 each even number replaced by " 0 " and each odd number replaced by " 1 " and the binary row RI is a binary representation of the Row ri:

Table 2. Binary Representation of $Z / 15 Z$.

\begin{tabular}{llllllllllllllll}
\hline R0 & 0 & 0 & 0 & 0 & 0 & 0 & 0 & 0 & 0 & 0 & 0 & 0 & 0 & 0 & 0 \\
R1 & 0 & 1 & 0 & 1 & 0 & 1 & 0 & 1 & 0 & 1 & 0 & 1 & 0 & 1 & 0 \\
R2 & 0 & 0 & 0 & 0 & 0 & 0 & 0 & 0 & 1 & 1 & 1 & 1 & 1 & 1 & 1 \\
R3 & 0 & 1 & 0 & 1 & 0 & 0 & 1 & 0 & 1 & 0 & 0 & 1 & 0 & 1 & 0 \\
R4 & 0 & 0 & 0 & 0 & 1 & 1 & 1 & 1 & 0 & 0 & 0 & 0 & 1 & 1 & 1 \\
R5 & 0 & 1 & 0 & 0 & 1 & 0 & 0 & 1 & 0 & 0 & 1 & 0 & 0 & 1 & 0 \\
R6 & 0 & 0 & 0 & 1 & 1 & 0 & 0 & 0 & 1 & 1 & 0 & 0 & 0 & 1 & 1 \\
R7 & 0 & 1 & 0 & 0 & 1 & 1 & 0 & 0 & 1 & 1 & 0 & 0 & 1 & 1 & 0 \\
R8 & 0 & 0 & 1 & 1 & 0 & 0 & 1 & 1 & 0 & 0 & 1 & 1 & 0 & 0 & 1 \\
R9 & 0 & 1 & 1 & 0 & 0 & 0 & 1 & 1 & 0 & 0 & 0 & 1 & 1 & 0 & 0 \\
R10 & 0 & 0 & 1 & 0 & 0 & 1 & 0 & 0 & 1 & 0 & 0 & 1 & 0 & 0 & 1 \\
R11 & 0 & 1 & 1 & 1 & 0 & 0 & 0 & 0 & 1 & 1 & 1 & 1 & 0 & 0 & 0 \\
R12 & 0 & 0 & 1 & 0 & 1 & 0 & 0 & 1 & 0 & 1 & 0 & 0 & 1 & 0 & 1 \\
R13 & 0 & 1 & 1 & 1 & 1 & 1 & 1 & 1 & 0 & 0 & 0 & 0 & 0 & 0 & 0 \\
R14 & 0 & 0 & 1 & 0 & 1 & 0 & 1 & 0 & 1 & 0 & 1 & 0 & 1 & 0 & 1 \\
\hline
\end{tabular}

From table 2:

1) All entries in the R0 are " 0 " and does not meet the conditions of orthogonal.

2) Each row of the R3, R5, R6, R9, R10, R12 contains 9 or 10 of " $0 . s$ " and 6 or 5 of " $1 . s$ " and does not meet the first conditions of orthogonal.

3) Each row of the R1, R2, R4, R7, R8, R11, R13, 14 contains $(15+1) / 2$ of " $0 . \mathrm{s}$ " and (15-1)/2 of " $1 . \mathrm{s"}$ " and the first condition of orthogonal is verified.

4) The basic rows R1, R2, R4, R7 are the conjugates of $\mathrm{R} 14, \mathrm{R} 13, \mathrm{R} 11, \mathrm{R} 8$ respectively and $\mathrm{R} 1+\mathrm{R} 14=\mathrm{R} 2+\mathrm{R} 13$ $=\mathrm{R} 4+\mathrm{R} 11=\mathrm{R} 7+\mathrm{R} 8=[011 \ldots 1]_{15}$.

The following table 3 showing the addition of some of the rows in the set where $\mathrm{R} i+\mathrm{R} j$ denoted by $\mathrm{R} i+j$. able 3 showing the addition between the rows $\{\mathrm{R} 1, \mathrm{R} 2, \mathrm{R} 3, \mathrm{R} 4\}$.

Table 3. Addition between the rows $\{R 1, R 2, R 4\}$.

\begin{tabular}{|c|c|c|c|c|c|c|c|c|c|c|c|c|c|c|c|}
\hline $\mathrm{R} 1$ & 0 & 1 & 0 & 1 & 0 & 1 & 0 & 1 & 0 & 1 & 0 & 1 & 0 & 1 & 0 \\
\hline $\mathrm{R} 2$ & 0 & 0 & 0 & 0 & 0 & 0 & 0 & 0 & 1 & 1 & 1 & 1 & 1 & 1 & 1 \\
\hline $\mathrm{R} 4$ & 0 & 0 & 0 & 0 & 1 & 1 & 1 & 1 & 0 & 0 & 0 & 0 & 1 & 1 & 1 \\
\hline $\mathrm{R} 1+4$ & 0 & 1 & 0 & 1 & 1 & 0 & 1 & 0 & 0 & 1 & 0 & 1 & 1 & 0 & 1 \\
\hline $\mathrm{R} 2+4$ & 0 & 0 & 0 & 0 & 1 & 1 & 1 & 1 & 1 & 1 & 1 & 1 & 0 & 0 & 0 \\
\hline $\mathrm{R} 1+2+4$ & 0 & 1 & 0 & 1 & 1 & 0 & 1 & 0 & 1 & 0 & 1 & 0 & 0 & 1 & 0 \\
\hline $\mathrm{R} 1+7$ & 0 & 0 & 0 & 1 & 1 & 0 & 1 & 0 & 1 & 0 & 1 & 1 & 1 & 0 & 0 \\
\hline $\mathrm{R} 2+7$ & 0 & 1 & 0 & 0 & 1 & 1 & 0 & 0 & 0 & 0 & 1 & 1 & 0 & 0 & 1 \\
\hline
\end{tabular}

From table 3 we can see R $2+7$ contains 9 of " $0 . s$ " and 6 of "1.s" and does not satisfy the condition of orthogonal, also $\operatorname{Span}\{\mathrm{R} 1, \mathrm{R} 2, \mathrm{R} 4\}$ without R0 is $\{\mathrm{R} 1, \mathrm{R} 2, \mathrm{R} 4, \mathrm{R} 1+2, \mathrm{R} 1+4$, $\mathrm{R} 2+4\}$ is a maximum closed orthogonal set contained in $F_{2} 15$, where $\{\mathrm{R} 1+2, \mathrm{R} 1+4, \mathrm{R} 2+4\}$ is not including in binary representation of $\mathrm{Z} / 15 \mathrm{Z}$, and the number of these maximum closed orthogonal sets is at most $\left(\begin{array}{c}\varphi(3) \cdot \varphi(5) \\ 3\end{array}\right)=\left(\begin{array}{c}2(4) \\ 3\end{array}\right)=\left(\begin{array}{l}8 \\ 3\end{array}\right)=56$ sets with the dimension 3, size or capacity is 7 , and minimum distance 6 of each a set. 


\subsection{2. $n=(3)(7)=21$}

For the quotient ring $Z / 21 Z$ the multiplication table of $Z / 21 Z$ is the following table 4 :

Table 4. Multiplication Table of Z/21Z

\begin{tabular}{|c|c|c|c|c|c|c|c|c|c|c|c|c|c|c|c|c|c|c|c|c|c|c|}
\hline & $*$ & O & 1 & 2 & 3 & 4 & 5 & 6 & 7 & 8 & 9 & 10 & 11 & 12 & 13 & 14 & 15 & 16 & 17 & 18 & 19 & 20 \\
\hline ro & 0 & 0 & 0 & 0 & 0 & 0 & 0 & 0 & 0 & 0 & 0 & 0 & 0 & 0 & 0 & 0 & 0 & 0 & 0 & 0 & 0 & 0 \\
\hline$r 1$ & 1 & 0 & 1 & 2 & 3 & 4 & 5 & 6 & 7 & 8 & 9 & 10 & 11 & 12 & 13 & 14 & 15 & 16 & 17 & 18 & 19 & 20 \\
\hline$r 2$ & 2 & 0 & 2 & 4 & 6 & 8 & 10 & 12 & 14 & 16 & 18 & 20 & 1 & 3 & 5 & 7 & 9 & 11 & 13 & 15 & 17 & 19 \\
\hline$r 3$ & 3 & 0 & 3 & 6 & 9 & 12 & 15 & 18 & 0 & 3 & 6 & 9 & 12 & 15 & 18 & 0 & 3 & 6 & 9 & 12 & 15 & 18 \\
\hline$r 4$ & 4 & 0 & 4 & 8 & 12 & 16 & 20 & 3 & 7 & 11 & 15 & 19 & 2 & 6 & 10 & 14 & 18 & 1 & 5 & 9 & 13 & 17 \\
\hline$r 5$ & 5 & 0 & 5 & 10 & 15 & 20 & 4 & 9 & 14 & 19 & 3 & 8 & 13 & 18 & 2 & 7 & 12 & 17 & 1 & 6 & 11 & 16 \\
\hline$r 6$ & 6 & 0 & 6 & 12 & 18 & 3 & 9 & 15 & 0 & 6 & 12 & 18 & 3 & 9 & 15 & 0 & 6 & 12 & 18 & 3 & 9 & 15 \\
\hline$r 7$ & 7 & 0 & 7 & 14 & 0 & 7 & 14 & 0 & 7 & 14 & 0 & 7 & 14 & 0 & 7 & 14 & 0 & 7 & 14 & 0 & 7 & 14 \\
\hline$r 8$ & 8 & 0 & 8 & 16 & 3 & 11 & 19 & 6 & 14 & 1 & 9 & 17 & 4 & 12 & 20 & 7 & 15 & 2 & 10 & 18 & 5 & 13 \\
\hline$r 9$ & 9 & 0 & 9 & 18 & 6 & 15 & 3 & 12 & 0 & 9 & 18 & 6 & 15 & 3 & 12 & 0 & 9 & 18 & 6 & 15 & 3 & 12 \\
\hline$r 10$ & 10 & 0 & 10 & 20 & 9 & 19 & 8 & 18 & 7 & 17 & 6 & 16 & 5 & 15 & 4 & 14 & 3 & 13 & 2 & 12 & 1 & 11 \\
\hline$r 11$ & 11 & 0 & 11 & 1 & 12 & 2 & 13 & 3 & 14 & 4 & 15 & 5 & 16 & 6 & 17 & 7 & 18 & 8 & 19 & 9 & 20 & 10 \\
\hline$r 12$ & 12 & 0 & 12 & 3 & 15 & 6 & 18 & 9 & 0 & 12 & 3 & 15 & 6 & 18 & 9 & 0 & 12 & 3 & 15 & 6 & 18 & 9 \\
\hline$r 13$ & 13 & 0 & 13 & 5 & 18 & 10 & 2 & 15 & 7 & 20 & 12 & 4 & 17 & 9 & 1 & 14 & 6 & 19 & 11 & 3 & 16 & 8 \\
\hline$r 14$ & 14 & 0 & 14 & 7 & 0 & 14 & 7 & 0 & 14 & 7 & 0 & 14 & 7 & 0 & 14 & 7 & 0 & 14 & 7 & 0 & 14 & 7 \\
\hline$r 15$ & 15 & 0 & 15 & 9 & 3 & 18 & 12 & 6 & 0 & 15 & 9 & 3 & 18 & 12 & 6 & 0 & 15 & 9 & 3 & 18 & 12 & 6 \\
\hline$r 16$ & 16 & 0 & 16 & 11 & 6 & 1 & 17 & 12 & 7 & 2 & 18 & 13 & 8 & 3 & 19 & 14 & 9 & 4 & 20 & 15 & 10 & 5 \\
\hline$r 17$ & 17 & 0 & 17 & 13 & 9 & 5 & 1 & 18 & 14 & 10 & 6 & 2 & 19 & 15 & 11 & 7 & 3 & 20 & 16 & 12 & 8 & 4 \\
\hline$r 18$ & 18 & 0 & 18 & 15 & 12 & 9 & 6 & 3 & 0 & 18 & 15 & 12 & 9 & 6 & 3 & 0 & 18 & 15 & 12 & 9 & 6 & 3 \\
\hline$r 19$ & 19 & 0 & 19 & 17 & 15 & 13 & 11 & 9 & 7 & 5 & 3 & 1 & 20 & 18 & 16 & 14 & 12 & 10 & 8 & 6 & 4 & 2 \\
\hline$r 20$ & 20 & 0 & 20 & 19 & 18 & 17 & 16 & 15 & 14 & 13 & 12 & 11 & 10 & 9 & 8 & 7 & 6 & 5 & 4 & 3 & 2 & 1 \\
\hline
\end{tabular}

We can see that $1,2,4,5,8,10,11,13,16,17,19,20$ are relatively prime with 21 and $r 1+r 20=r 2+r 19=r 4+r 17=$ $r 5+r 16=r 8+r 13=r 10+r 11=[00 \ldots 0]_{21}$.

Table 5 showing the binary representation of table 4 , when in the table 4 each even number replaced by " 0 " and each odd number replaced by " 1 ". The binary representation of table 4 is the table 5 :

Table 5. Binary Representation of Multiplication table of $Z / 21 Z$.

\begin{tabular}{lllllllllllllllllllllllll}
\hline Ro & 0 & 0 & 0 & 0 & 0 & 0 & 0 & 0 & 0 & 0 & 0 & 0 & 0 & 0 & 0 & 0 & 0 & 0 & 0 & 0 & 0 \\
R1 & 0 & 1 & 0 & 1 & 0 & 1 & 0 & 1 & 0 & 1 & 0 & 1 & 0 & 1 & 0 & 1 & 0 & 1 & 0 & 1 & 0 \\
R2 & 0 & 0 & 0 & 0 & 0 & 0 & 0 & 0 & 0 & 0 & 0 & 1 & 1 & 1 & 1 & 1 & 1 & 1 & 1 & 1 & 1 \\
R3 & 0 & 1 & 0 & 1 & 0 & 1 & 0 & 0 & 1 & 0 & 1 & 0 & 1 & 0 & 0 & 1 & 0 & 1 & 0 & 1 & 0 \\
R4 & 0 & 0 & 0 & 0 & 0 & 0 & 1 & 1 & 1 & 1 & 1 & 0 & 0 & 0 & 0 & 0 & 1 & 1 & 1 & 1 & 1 \\
R5 & 0 & 1 & 0 & 1 & 0 & 0 & 1 & 0 & 1 & 1 & 0 & 1 & 0 & 0 & 1 & 0 & 1 & 1 & 0 & 1 & 0 \\
R6 & 0 & 0 & 0 & 0 & 1 & 1 & 1 & 0 & 0 & 0 & 0 & 1 & 1 & 1 & 0 & 0 & 0 & 0 & 1 & 1 & 1 \\
R7 & 0 & 1 & 0 & 0 & 1 & 0 & 0 & 1 & 0 & 0 & 1 & 0 & 0 & 1 & 0 & 0 & 1 & 0 & 0 & 1 & 0 \\
R8 & 0 & 0 & 0 & 1 & 1 & 1 & 0 & 0 & 1 & 1 & 1 & 0 & 0 & 0 & 1 & 1 & 0 & 0 & 0 & 1 & 1 \\
R9 & 0 & 1 & 0 & 0 & 1 & 1 & 0 & 0 & 1 & 0 & 0 & 1 & 1 & 0 & 0 & 1 & 0 & 0 & 1 & 1 & 0 \\
R10 & 0 & 0 & 0 & 1 & 1 & 0 & 0 & 1 & 1 & 0 & 0 & 1 & 1 & 0 & 0 & 1 & 1 & 0 & 0 & 1 & 1 \\
R11 & 0 & 1 & 1 & 0 & 0 & 1 & 1 & 0 & 0 & 1 & 1 & 0 & 0 & 1 & 1 & 0 & 0 & 1 & 1 & 0 & 0 \\
R12 & 0 & 0 & 1 & 1 & 0 & 0 & 1 & 0 & 0 & 1 & 1 & 0 & 0 & 1 & 0 & 0 & 1 & 1 & 0 & 0 & 1 \\
R13 & 0 & 1 & 1 & 0 & 0 & 0 & 1 & 1 & 0 & 0 & 0 & 1 & 1 & 1 & 0 & 0 & 1 & 1 & 1 & 0 & 0 \\
R14 & 0 & 0 & 1 & 0 & 0 & 1 & 0 & 0 & 1 & 0 & 0 & 1 & 0 & 0 & 1 & 0 & 0 & 1 & 0 & 0 & 1 \\
R15 & 0 & 1 & 1 & 1 & 0 & 0 & 0 & 0 & 1 & 1 & 1 & 0 & 0 & 0 & 0 & 1 & 1 & 1 & 0 & 0 & 0 \\
R16 & 0 & 0 & 1 & 0 & 1 & 1 & 0 & 1 & 0 & 0 & 1 & 0 & 1 & 1 & 0 & 1 & 0 & 0 & 1 & 0 & 1 \\
R17 & 0 & 1 & 1 & 1 & 1 & 1 & 0 & 0 & 0 & 0 & 0 & 1 & 1 & 1 & 1 & 1 & 0 & 0 & 0 & 0 & 0 \\
R18 & 0 & 0 & 1 & 0 & 1 & 0 & 1 & 0 & 0 & 1 & 0 & 1 & 0 & 1 & 0 & 0 & 1 & 0 & 1 & 0 & 1 \\
R19 & 0 & 1 & 1 & 1 & 1 & 1 & 1 & 1 & 1 & 1 & 1 & 0 & 0 & 0 & 0 & 0 & 0 & 0 & 0 & 0 & 2 \\
R20 & 0 & 0 & 1 & 0 & 1 & 0 & 1 & 0 & 1 & 0 & 1 & 0 & 1 & 0 & 1 & 0 & 1 & 0 & 1 & 0 & 1 \\
\hline
\end{tabular}

From table 5:

1) All entries in the R0 are " 0 " and does not meet the conditions of orthogonal.

2) Each row of the R3, R6, R7, R9, R12, R14, R15, R18 contains 12 or 14 of " $0 . \mathrm{s"}$ " and 9 or 7 of " $1 . s$ " and does not meet the first conditions of orthogonal except R9 contains 11 of " $0 . s$ " and 10 of " $1 . s " . ~ R 2+R 9$ contains 12 of "0.s" and 9 of " $1 . s "$

3) Each row of the R1, R2, R5, R8, R10, R11, R13, R14, $\mathrm{R} 16, \mathrm{R} 17, \mathrm{R} 19, \mathrm{R} 20$ contains $(21+1) / 2$ of " $0 . \mathrm{s}$ " and (21$1) / 2$ of " $1 . s$ " and the first condition of orthogonal is verified. 
4) The basic rows $R 1, R 2, R 4, R 5, R 8, R 10$ are the conjugates of R20, R19, R17, R16, R13, R11 respectively and $\mathrm{R} 1+\mathrm{R} 20=\mathrm{R} 2+\mathrm{R} 19=\mathrm{R} 4+\mathrm{R} 17=$ $\mathrm{R} 5+\mathrm{R} 16=\mathrm{R} 8+\mathrm{R} 13=\mathrm{R} 10+\mathrm{R} 11=[011 \ldots 1]_{21}$.

5) $\mathrm{R} i$ and its conjugate $\mathrm{R}(n-i)$ can't be in one Span, each of
$\mathrm{R} 1+\mathrm{R} 4$ and R2+R8 contain 9 of " $0 . \mathrm{s}$ " and 12 of " $1 . \mathrm{s}$ ", $\mathrm{R} 2+\mathrm{R} 9$ contains 12 of " $0 . \mathrm{s}$ " and 9 of " $1 . \mathrm{s",}$, and each of $\mathrm{R} 1+\mathrm{R} 5$ and R2+R10 contain 13 of " $0 . \mathrm{s}$ " and 8 of " $1 . \mathrm{s"}$ ".

Table 6 showing Sum R1 with R4 and R5 and table 7 showing the sum R2 with R8, R9, and R10

Table 6. Sum R1 with R4 and R5.

\begin{tabular}{llllllllllllllllllllllll}
\hline $\mathrm{R} 1+4$ & 0 & 1 & 0 & 1 & 0 & 1 & 1 & 0 & 1 & 0 & 1 & 1 & 0 & 1 & 0 & 1 & 1 & 0 & 1 & 0 & 1 \\
$\mathrm{R} 1+5$ & 0 & 0 & 0 & 0 & 0 & 1 & 1 & 1 & 1 & 0 & 0 & 0 & 0 & 1 & 1 & 1 & 1 & 0 & 0 & 0 & 0 \\
\hline
\end{tabular}

Table 7. Sum R2 with R8, R9, and R10.

\begin{tabular}{llllllllllllllllllllllll}
\hline R2+R8 & 0 & 0 & 0 & 1 & 1 & 1 & 0 & 0 & 1 & 1 & 1 & 1 & 1 & 1 & 0 & 0 & 1 & 1 & 1 & 0 & 0 \\
R2+R9 & 0 & 1 & 0 & 0 & 1 & 1 & 0 & 0 & 1 & 0 & 0 & 0 & 0 & 1 & 1 & 0 & 1 & 1 & 0 & 0 & 1 \\
R2+R10 & 0 & 0 & 0 & 1 & 1 & 0 & 0 & 1 & 1 & 0 & 0 & 0 & 0 & 1 & 1 & 0 & 0 & 1 & 1 & 0 & 0 \\
\hline
\end{tabular}

Thus; R1, R4, R5 can't be in one Span and the same for R2, R8, R9, R10.

6) The following table showing the addition between some of the rows in the set where $\mathrm{R} i+\mathrm{Rj}$ denoted by $\mathrm{R} i+j$.

Table 8 showing the sum of the row R1 with the row R2:

Table 8. Sum R1 with R2.

\begin{tabular}{lllllllllllllllllllllllll}
\hline R1 & 0 & 1 & 0 & 1 & 0 & 1 & 0 & 1 & 0 & 1 & 0 & 1 & 0 & 1 & 0 & 1 & 0 & 1 & 0 & 1 & 0 & 1 \\
R2 & 0 & 0 & 0 & 0 & 0 & 0 & 0 & 0 & 0 & 0 & 0 & 1 & 1 & 1 & 1 & 1 & 1 & 1 & 1 & 1 & 1 & \\
$\mathrm{R} 1+2$ & 0 & 1 & 0 & 1 & 0 & 1 & 0 & 1 & 0 & 1 & 0 & 0 & 1 & 0 & 1 & 0 & 1 & 0 & 1 & 0 & 1 \\
\hline
\end{tabular}

$\operatorname{Span}\{\mathrm{R} 1, \mathrm{R} 2\}$ without $\mathrm{R} 0$ is $\{\mathrm{R} 1, \mathrm{R} 2, \mathrm{R} 1+2\}$ is a maximum closed orthogonal set contained in $F_{2} 21$, where $\{\mathrm{R} 1+2, \mathrm{R} 1+4, \mathrm{R} 2+4\}$ is not including in binary representation of $\mathrm{Z} / 21 \mathrm{Z}$, and the number of these maximum closed orthogonal sets is at most $\left(\begin{array}{c}\varphi(3) \cdot \varphi(7) \\ 2\end{array}\right)=\left(\begin{array}{c}2(6) \\ 2\end{array}\right)=\left(\begin{array}{l}12 \\ 2\end{array}\right)=66$ sets with the dimension 2 and the size 3 of each a set, and minimum distance 10 , while the expected dimensions and sizes for each of set are at least 4 and 17 respectively.

\subsection{3. $n=5(7)=35$}

The following table 9 showing the multiple in the quotient ring $Z / 35 Z$ with restriction over the basic useful numbers which are relatively prime with 35 (are half of the numbers which are relatively prime with 35 ).

Table 9. Multiplication table of $Z / 35 Z$

\begin{tabular}{llllllllllllllllllllllllllllllllllllllllllllllll}
\hline & $*$ & $\mathbf{0}$ & $\mathbf{1}$ & $\mathbf{2}$ & $\mathbf{3}$ & $\mathbf{4}$ & $\mathbf{5}$ & $\mathbf{6}$ & $\mathbf{7}$ & $\mathbf{8}$ & $\mathbf{9}$ & $\mathbf{1 0}$ & $\mathbf{1 1}$ & $\mathbf{1 2}$ & $\mathbf{1 3}$ & $\mathbf{1 4}$ & $\mathbf{1 5}$ & $\mathbf{1 6}$ & $\mathbf{1 7}$ & $\mathbf{1 8}$ & $\mathbf{1 9}$ & $\mathbf{2 0}$ & $\mathbf{2 1}$ & $\mathbf{2 2}$ & $\mathbf{2 3}$ & $\mathbf{2 4}$ & $\mathbf{2 5}$ & $\mathbf{2 6}$ & $\mathbf{2 7}$ & $\mathbf{2 8}$ & $\mathbf{2 9}$ & $\mathbf{3 0}$ & $\mathbf{3 1}$ & $\mathbf{3 2}$ & $\mathbf{3 3}$ & $\mathbf{3 4}$ \\
\hline $\mathrm{r} 1$ & 1 & 0 & 1 & 2 & 3 & 4 & 5 & 6 & 7 & 8 & 9 & 10 & 11 & 12 & 13 & 14 & 15 & 16 & 17 & 18 & 19 & 20 & 21 & 22 & 23 & 24 & 25 & 26 & 27 & 28 & 29 & 30 & 31 & 32 & 33 & 34 \\
$\mathrm{r} 2$ & 2 & 0 & 2 & 4 & 6 & 8 & 10 & 12 & 14 & 16 & 18 & 20 & 22 & 24 & 26 & 28 & 30 & 32 & 34 & 13 & 5 & 7 & 9 & 11 & 13 & 15 & 17 & 19 & 21 & 23 & 25 & 27 & 29 & 31 & 33 & & \\
$\mathrm{r} 3$ & 3 & 0 & 3 & 6 & 9 & 12 & 15 & 18 & 21 & 24 & 27 & 30 & 33 & 1 & 4 & 7 & 10 & 13 & 16 & 19 & 22 & 25 & 28 & 31 & 34 & 2 & 5 & 8 & 11 & 14 & 17 & 20 & 23 & 26 & 29 & 32 \\
$\mathrm{r} 4$ & 4 & 0 & 4 & 8 & 12 & 16 & 20 & 24 & 28 & 32 & 1 & 5 & 9 & 13 & 17 & 21 & 25 & 29 & 33 & 2 & 6 & 10 & 14 & 18 & 22 & 26 & 30 & 34 & 3 & 7 & 11 & 15 & 19 & 23 & 27 & 31 \\
$\mathrm{r} 6$ & 6 & 0 & 6 & 12 & 18 & 24 & 30 & 17 & 13 & 19 & 25 & 31 & 2 & 8 & 14 & 20 & 26 & 32 & 3 & 9 & 15 & 21 & 27 & 33 & 4 & 10 & 16 & 22 & 28 & 34 & 5 & 11 & 17 & 23 & 29 & \\
$\mathrm{r} 8$ & 8 & 0 & 8 & 16 & 24 & 32 & 5 & 13 & 21 & 29 & 2 & 10 & 18 & 26 & 34 & 7 & 15 & 23 & 31 & 4 & 12 & 20 & 28 & 1 & 9 & 17 & 25 & 33 & 6 & 14 & 22 & 30 & 3 & 11 & 19 & 27 \\
$\mathrm{r} 9$ & 9 & 0 & 9 & 18 & 27 & 1 & 10 & 19 & 28 & 2 & 11 & 20 & 29 & 3 & 12 & 21 & 30 & 4 & 13 & 22 & 31 & 5 & 14 & 23 & 32 & 6 & 15 & 24 & 33 & 7 & 16 & 25 & 34 & 8 & 17 & 26 \\
r11 & 11 & 0 & 11 & 22 & 33 & 9 & 20 & 31 & 7 & 18 & 29 & 5 & 16 & 27 & 3 & 14 & 25 & 1 & 12 & 23 & 34 & 10 & 21 & 32 & 8 & 19 & 30 & 6 & 17 & 28 & 4 & 15 & 26 & 2 & 13 & 24 \\
r12 & 12 & 0 & 12 & 24 & 1 & 13 & 25 & 2 & 14 & 26 & 3 & 15 & 27 & 4 & 16 & 28 & 5 & 17 & 29 & 6 & 18 & 30 & 7 & 19 & 31 & 8 & 20 & 32 & 9 & 21 & 33 & 10 & 22 & 34 & 11 & 23 \\
r13 & 13 & 0 & 13 & 26 & 4 & 17 & 30 & 8 & 21 & 34 & 12 & 25 & 3 & 16 & 29 & 7 & 20 & 33 & 11 & 24 & 2 & 15 & 28 & 6 & 19 & 32 & 10 & 23 & 1 & 14 & 27 & 5 & 18 & 31 & 9 & 22 \\
r16 & 16 & 0 & 16 & 32 & 13 & 29 & 10 & 26 & 7 & 23 & 4 & 20 & 1 & 17 & 33 & 14 & 30 & 11 & 27 & 8 & 24 & 5 & 21 & 2 & 18 & 34 & 15 & 31 & 12 & 28 & 9 & 25 & 6 & 22 & 3 & 19 \\
r17 & 17 & 0 & 17 & 34 & 16 & 33 & 15 & 32 & 14 & 31 & 13 & 30 & 12 & 29 & 11 & 28 & 10 & 27 & 9 & 26 & 8 & 25 & 7 & 24 & 6 & 23 & 5 & 22 & 4 & 21 & 3 & 20 & 2 & 19 & 1 & 18 \\
\hline
\end{tabular}

The binary representation of table 9 showing in the following table 10:

Table 10. Binary representation of table 9.

\begin{tabular}{|c|c|c|c|c|c|c|c|c|}
\hline $\mathrm{R} 1$ & 0 & 10101 & 01010 & 10101 & 01010 & 10101 & 01010 & 1010 \\
\hline $\mathrm{R} 2$ & 0 & 00000 & 00000 & 00000 & 000111 & $\begin{array}{lllll}11 & 1 & 1 & 1\end{array}$ & 11111 & 1111 \\
\hline R3 & 0 & 10101 & 01010 & 11010 & 10101 & 01001 & 01010 & 1010 \\
\hline R4 & 0 & 00000 & $\begin{array}{lllll}0 & 0 & 0 & 1 & 1\end{array}$ & 11111 & 11000 & 00000 & $0 \begin{array}{llll}0 & 1 & 1 & 1\end{array}$ & 1111 \\
\hline R6 & 0 & 00000 & 11111 & 10000 & 000111 & 11100 & 000001 & 1111 \\
\hline R8 & 0 & 00001 & 11100 & 000011 & 11000 & $\begin{array}{llllll}0 & 1 & 1 & 1 & 1\end{array}$ & 10000 & 1111 \\
\hline R9 & 0 & 10110 & 10010 & 11010 & 0101011 & 01001 & 011101 & 0010 \\
\hline R11 & 0 & 10110 & 11011 & 011101 & 10100 & 10010 & 01001 & 0010 \\
\hline
\end{tabular}




\begin{tabular}{lllllllll}
\hline R13 & 0 & 10010 & 01001 & 10110 & 11001 & 00100 & 11011 & 0110 \\
R16 & 0 & 00110 & 01100 & 11100 & 11001 & 1001 & 10011 & 0011 \\
R17 & 0 & 10011 & 00110 & 01100 & 11001 & 10011 & 00110 & 0110 \\
\hline
\end{tabular}

From table 10:

1) All entries in the R0 are " 0 " and does not meet the conditions of orthogonal.

2) Each row of the R5, R7, R10, R14, R15, R20, R21, $\mathrm{R} 25, \mathrm{R} 28, \mathrm{R} 30$, contains 20 or 21 of " $0 . \mathrm{s}$ " and 15 or 14 of "1.s" and does not meet the first conditions of orthogonal.

3) Each row of the R1, R2, R3, R4, R6, R8, R9, R11, R12, $\mathrm{R} 13, \mathrm{R} 16, \mathrm{R} 17$ or their conjugates (by mode 35) contains $(35+1) / 2$ of " $0 . s "$ and $(35-1) / 2$ of " $1 . s$ " and the first condition of orthogonal is verified.

4) $\mathrm{R} i$ and its conjugate $\mathrm{R}(n-i)$ can't be in one Span, each of $\mathrm{R} 1+3, \mathrm{R} 1+4, \mathrm{R} 1+9, \mathrm{R} 1+12, \mathrm{R} 1+13, \mathrm{R} 1+17, \mathrm{R} 2+6$, $\mathrm{R} 2+8$, and $\mathrm{R} 2+11$ does not meet the first conditions of orthogonal and can't be in one Span.

Table 11 showing the sum of R1 and R2 with the some other rows.

Table 11. Sum $R 1$ and $R 2$ with some other rows.

\begin{tabular}{|c|c|c|c|c|c|c|c|c|}
\hline $\mathrm{R} 1+3$ & 0 & 00000 & 00000 & 011111 & 11111 & 11100 & 00000 & 0000 \\
\hline $\mathrm{R} 1+4$ & 0 & 10101 & 010001 & 01010 & 10010 & 10100 & 0010101 & $\begin{array}{llll}0 & 1 & 0 & 1\end{array}$ \\
\hline $\mathrm{R} 1+9$ & 0 & 000011 & 11000 & 011111 & $\begin{array}{lllll}0 & 0 & 0 & 0 & 1\end{array}$ & 11100 & 000011 & 1000 \\
\hline $\mathrm{R} 1+12$ & 0 & 10010 & 01001 & 00100 & 10010 & 01001 & 00100 & 1001 \\
\hline $\mathrm{R} 1+13$ & 0 & $\begin{array}{lllll}0 & 0 & 1 & 1 & 1\end{array}$ & $\begin{array}{lllll}0 & 0 & 0 & 1 & 1\end{array}$ & 000011 & 10011 & 10001 & 10001 & 1100 \\
\hline $\mathrm{R} 1+17$ & 0 & 00010 & 01100 & 11001 & 10011 & 00110 & 01100 & 1100 \\
\hline $\mathrm{R} 2+6$ & 0 & 00000 & 11110 & 10000 & 00000 & 000011 & 11110 & 0000 \\
\hline $\mathrm{R} 2+11$ & 0 & 10110 & 11011 & 01101 & 10011 & 01101 & 10110 & 1101 \\
\hline
\end{tabular}

5) The following table showing the addition between some of the rows in the set where

$\mathrm{R} i+\mathrm{R} j$ denoted by $\mathrm{R} i+j$. Table 12 showing the of Span R1, R2 and R16.

Table 12. Span R1, R2 and R16.

\begin{tabular}{|c|c|c|c|c|c|c|c|c|}
\hline $\mathrm{R} 1$ & 0 & 10101 & 01010 & 10101 & 01010 & 10101 & 01010 & 1010 \\
\hline $\mathrm{R} 2$ & 0 & 00000 & 00000 & 00000 & 0001111 & $\begin{array}{lllll}1 & 1 & 1 & 1 & 1\end{array}$ & $\begin{array}{lllll}11 & 1 & 1 & 1\end{array}$ & 1111 \\
\hline R16 & 0 & 00110 & 011100 & 11100 & 11001 & 10001 & 10011 & $\begin{array}{llll}0 & 0 & 1 & 1\end{array}$ \\
\hline $\mathrm{R} 1+2$ & 0 & 10101 & 01010 & 10101 & 011101 & 01010 & 10101 & 0101 \\
\hline $\mathrm{R} 1+16$ & 0 & 10111 & 001110 & 01001 & 10011 & 00100 & 11001 & 1001 \\
\hline $\mathrm{R} 2+16$ & 0 & 00110 & 011100 & 11100 & 11110 & 011110 & 01100 & 1100 \\
\hline $\mathrm{R} 1+2+16$ & 0 & 10011 & 00110 & 01001 & 10100 & 11011 & 00110 & 0110 \\
\hline
\end{tabular}

Span $\{\mathrm{R} 1, \mathrm{R} 2, \mathrm{R} 16\}$ without $\mathrm{R} 0$ is $\{\mathrm{R} 1, \mathrm{R} 2, \mathrm{R} 16, \mathrm{R} 1+2$, $\mathrm{R} 1+16, \mathrm{R} 2+16, \mathrm{R} 1+2+16\}$ is a maximum closed orthogonal set contained in $F_{2^{35}}$, where $\{\mathrm{R} 1+2, \mathrm{R} 1+16, \mathrm{R} 2+16$, $\mathrm{R} 1+2+16$ \} is not including in binary representation of $\mathrm{Z} / 35 \mathrm{Z}$, and the number of these maximum closed orthogonal sets is at $\operatorname{most}\left(\begin{array}{c}\varphi(5) \cdot \varphi(7) \\ 3\end{array}\right)=\left(\begin{array}{c}4(6) \\ 3\end{array}\right)\left(\begin{array}{c}24 \\ 3\end{array}\right)=2024$ sets with the dimension 3 and the size 7 of each a set, and minimum distance 17, while the expected dimension and size for each set are at least 5 and 31 respectively.

\subsection{4. $n=3^{2}(5)=45$}

The following table 8 showing the multiple in the ring $Z / 45 Z$ with restriction over the basic useful numbers which are relatively prime with 45 (are half of the numbers which are relatively prime with 45 .

Table 13. Multiplication table in $Z / 45 Z$

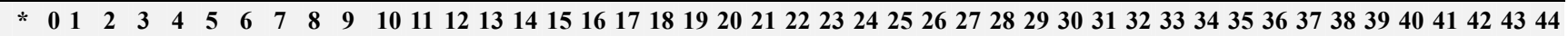

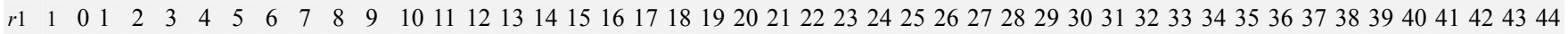

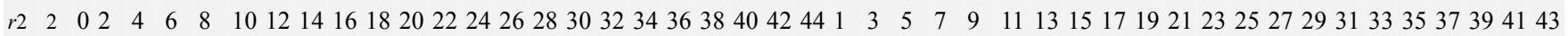
$r 4 \quad 4 \quad 04 \quad 8 \quad 1216202428323640443 \quad 7 \quad 11 \quad 15192327313539432 \quad 6 \quad 1014182226303438421 \quad 5 \quad 9 \quad 1317212529333741$

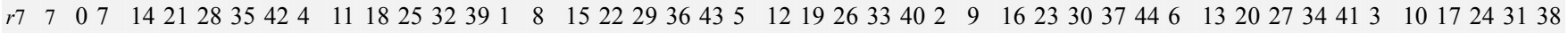

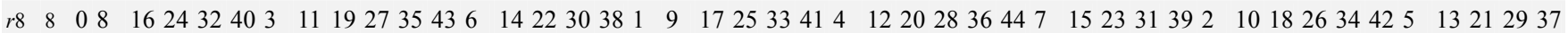

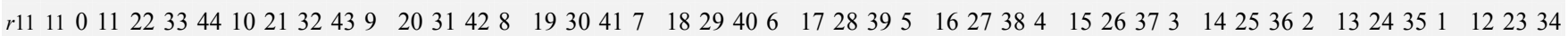
$r 131301326397203311427408 \quad 21342152841922353 \quad 1629421023364 \quad 1730431124375 \quad 1831441225386 \quad 1932$ $r 1414014284211253982236519332 \quad 163044132741102438721354183211152943122640923376 \quad 20343 \quad 1731$ $r 161601632319356 \quad 22389254112284415312 \quad 18345 \quad 21378 \quad 244011274314301117334 \quad 20367 \quad 23391026421329$ r17 $17017346234012291 \quad 18357 \quad 244113302 \quad 19368 \quad 254214313 \quad 20379 \quad 264315324 \quad 213810274416335 \quad 22391128$ 
$r 191901938123152443173610293224115348 \quad 2711203913326254418371130423421635928221401433726$

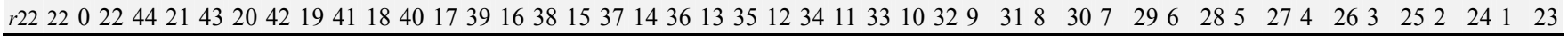

The binary representation of table 8 showing in the following table 14

Table 14. Binary representation of table 13.

\begin{tabular}{|c|c|c|c|c|c|c|c|c|c|c|}
\hline $\mathrm{R} 1$ & 0 & 10101 & 01010 & 10101 & 01010 & $\begin{array}{lllll}10 & 10 & 0\end{array}$ & 01010 & 10101 & 01010 & 1010 \\
\hline $\mathrm{R} 2$ & 0 & 00000 & 00000 & 00000 & 00000 & 000111 & $\begin{array}{lllll}11 & 1 & 1 & 1\end{array}$ & $\begin{array}{lllll}1 & 1 & 1 & 1\end{array}$ & $\begin{array}{lllll}11 & 11 & 1\end{array}$ & 1111 \\
\hline R4 & 0 & 00000 & 00000 & $0 \begin{array}{lllll}0 & 1 & 1 & 1 & 1\end{array}$ & 11111 & 11000 & 00000 & $\begin{array}{lllll}0 & 0 & 0 & 1 & 1\end{array}$ & 11111 & 1111 \\
\hline R7 & 0 & 10101 & $\begin{array}{lllll}0 & 0 & 1 & 0 & 1\end{array}$ & $\begin{array}{lllll}0 & 1 & 1 & 0 & 1\end{array}$ & $\begin{array}{lllll}0 & 1 & 0 & 1 & 1\end{array}$ & 01010 & $\begin{array}{lllll}0 & 1 & 0 & 1 & 0\end{array}$ & 10010 & 10110 & 1010 \\
\hline R11 & 0 & 10100 & 10110 & 10010 & 11010 & 0101011 & 01001 & 011101 & 00101 & 1010 \\
\hline $\mathrm{R} 13$ & 0 & 10110 & 11010 & $\begin{array}{lllll}0 & 1 & 0 & 0 & 1\end{array}$ & 011101 & 10100 & 10010 & 11011 & 01001 & 0010 \\
\hline $\mathrm{R} 14$ & 0 & 000011 & 10001 & 11000 & 011110 & 000111 & $\begin{array}{lllll}0 & 0 & 0 & 1 & 1\end{array}$ & 11000 & 11100 & $\begin{array}{llll}0 & 1 & 1 & 1\end{array}$ \\
\hline R17 & 0 & 10010 & $\begin{array}{lllll}0 & 1 & 1 & 0 & 1\end{array}$ & 10110 & $\begin{array}{lllll}0 & 1 & 0 & 0 & 1\end{array}$ & 000110 & 11011 & 00100 & 100011 & $\begin{array}{llll}0 & 1 & 1 & 0\end{array}$ \\
\hline R19 & 0 & $\begin{array}{lllll}1 & 0 & 0 & 1 & 1\end{array}$ & 01100 & 11011 & 00110 & 11001 & $\begin{array}{lllll}0 & 0 & 1 & 1 & 0\end{array}$ & 01001 & 10010 & 01110 \\
\hline R22 & 0 & 00110 & 011100 & 11001 & 10011 & 00110 & 011100 & 11001 & 1001 & $\begin{array}{llll}0 & 0 & 1 & 1\end{array}$ \\
\hline
\end{tabular}

From table 13 and binary representation of other rows in Z/45Z:

1) All entries in the R0 are " 0 " and does not meet the conditions of orthogonal.

2) Each row of the R3, R5, R6, R9, R10, R12, R15, $\mathrm{R} 18, \mathrm{R} 20, \mathrm{R} 21$ and their conjugates(by mode 45) does not meet the first conditions of orthogonal.

3) Each row of the R1, R2, R4, R7, R8, R11, R13, R14, $\mathrm{R} 16, \mathrm{R} 17, \mathrm{R} 19, \mathrm{R} 22$ or their conjugates contains
$(45+1) / 2$ of " $0 . s$ " and (45-1)/2 of " $1 . s$ " and the first condition of orthogonal is verified.

4) $\mathrm{R} i$ and its conjugate $\mathrm{R}(n-i)$ can't be in one Span and where $\mathrm{R} i+\mathrm{R} j$ denoted by $\mathrm{R} i+j$,

each of $\mathrm{R} 1+7, \mathrm{R} 1+11, \mathrm{R} 1+13, \mathrm{R} 1+4, \mathrm{R} 1+16, \mathrm{R} 1+19$, $\mathrm{R} 2+8, \mathrm{R} 2+17$ and $\mathrm{R} 2+22$ does not meet the first conditions of orthogonal and can't be in one Span. Table 15 showing the sum of R1 and R2 with some other rows.

Table 15. Sum R1 and R2 with some other rows.

\begin{tabular}{|c|c|c|c|c|c|c|c|c|c|c|}
\hline $\mathrm{R} 1+7$ & 0 & 00000 & 01111 & 11000 & 00001 & 11111 & 00000 & 00111 & 11100 & 0000 \\
\hline $\mathrm{R} 1+11$ & 0 & 00001 & 11100 & 00111 & 10000 & 11110 & 00011 & 11000 & 01111 & 0000 \\
\hline $\mathrm{R} 1+13$ & 0 & 00011 & 10000 & 11100 & 00111 & 00001 & 11000 & 01110 & 00011 & 1000 \\
\hline $\mathrm{R} 1+16$ & 0 & 10010 & 01001 & 00100 & 10011 & 01101 & 10110 & 01001 & 00100 & 1001 \\
\hline $\mathrm{R} 1+19$ & 0 & 00110 & 00110 & 01110 & 01100 & 01100 & 01100 & 11100 & 11000 & 1100 \\
\hline $\mathrm{R} 2+8$ & 0 & 00000 & 11111 & 10000 & 01111 & 11111 & 11100 & 00011 & 11110 & 0000 \\
\hline $\mathrm{R} 2+17$ & 0 & 10010 & 01101 & 10110 & 01001 & 00001 & 00100 & 11011 & 01100 & 1001 \\
\hline $\mathrm{R} 2+22$ & 0 & 00110 & 01100 & 11001 & 10011 & 00001 & 10011 & 00110 & 01100 & 1100 \\
\hline
\end{tabular}

The following table 16 showing the Span of R1, R2 and R4;

Table 16. Span R1, R2 and $R 4$.

\begin{tabular}{|c|c|c|c|c|c|c|c|c|c|c|}
\hline R1 & 0 & 10101 & 01010 & 10101 & 01010 & 10101 & 01010 & 10101 & 01010 & 1010 \\
\hline $\mathrm{R} 2$ & 0 & 00000 & 00000 & 00000 & 00000 & $\begin{array}{llllll}0 & 0 & 1 & 1 & 1\end{array}$ & 11111 & 11111 & 11111 & 1111 \\
\hline R4 & 0 & 00000 & 00000 & $\begin{array}{lllll}0 & 1 & 1 & 1 & 1\end{array}$ & 11111 & 11000 & 00000 & $\begin{array}{lllll}0 & 0 & 0 & 1 & 1\end{array}$ & 11111 & 1111 \\
\hline $\mathrm{R} 1+2$ & 0 & 10101 & 01010 & 10101 & 01010 & 10010 & 10101 & 01010 & 10101 & $\begin{array}{llll}0 & 1 & 0 & 1\end{array}$ \\
\hline $\mathrm{R} 1+4$ & 0 & 10101 & 01010 & 11010 & 01010 & $\begin{array}{lllll}0 & 1 & 1 & 0 & 1\end{array}$ & 01010 & 10110 & 10101 & $\begin{array}{llll}0 & 1 & 0 & 1\end{array}$ \\
\hline $\mathrm{R} 2+4$ & 0 & 00000 & 00000 & $0 \begin{array}{lllll}0 & 1 & 1 & 1 & 1\end{array}$ & 11111 & 11111 & 11111 & 11100 & 00000 & 0000 \\
\hline $\mathrm{R} 1+2+4$ & 0 & 10101 & 01010 & 11010 & 10101 & 01010 & 10101 & 01001 & 01010 & 1010 \\
\hline
\end{tabular}

Span $\{\mathrm{R} 1, \mathrm{R} 2, \mathrm{R} 4\}$ without $\mathrm{R} 0$ is $\{\mathrm{R} 1, \mathrm{R} 2, \mathrm{R} 4, \mathrm{R} 1+2$, $\mathrm{R} 1+4, \mathrm{R} 2+4, \mathrm{R} 1+2+4\}$ is a maximum closed orthogonal set contained in $F_{2} 45$, where $\{\mathrm{R} 1+2, \mathrm{R} 1+4, \mathrm{R} 2+4, \mathrm{R} 1+2+4\}$ is not including in binary representation of $\mathrm{Z} / 45 \mathrm{Z}$, and the number of these maximum closed orthogonal sets is at most $\left(\begin{array}{c}\varphi(9) \cdot \varphi(5) \\ 3\end{array}\right)=\left(\begin{array}{c}6(4) \\ 3\end{array}\right)\left(\begin{array}{c}24 \\ 3\end{array}\right)=2024$ sets with the dimension 3 and the size 7 of each a set, and minimum distance 22, while the expected dimensions and sizes for each of set are at least 5 and 31 respectively.

\section{2. n Is Even}

1) If the index $i$ is even then the entries in the row $r i$ in the table $\mathrm{Z} / n \mathrm{Z}$ contains only even numbers and its corresponding binary representation $\mathrm{R} i$ is zero row and 
does not satisfy the first condition of orthogonal.

2) If the index $i$ is odd then the entries in the row $r i$ in the table $\mathrm{Z} / n \mathrm{Z}$ contains one even entry and after one odd entry periodically and its corresponding binary representation $\mathrm{R} i$ the entries are one $\mathrm{o}$ and after 1 periodically and satisfies the first condition of orthogonal.

3) If the indexes $i, j$ is odd numbers the distribution of odd and even numbers the same in $r i$ and $r j$ and the distribution of " $0 . \mathrm{s}$ " and " $1 . \mathrm{s}$ " in $\mathrm{R} i$ and $\mathrm{R} j$ also the same and $\mathrm{R} i+j$ is the zero row. Thus if $n$ is even to $\mathrm{Z} / n \mathrm{Z}$ don't have orthogonal sets and the following tables of representation of $\mathrm{Z} / 10 \mathrm{Z}$ illustrated the ideas.

The following table 17 showing the multiplication on quotient ring $\mathrm{Z} / 10 \mathrm{Z}$ :

Table 17. multiplication on quotient ring Z/10Z.

\begin{tabular}{|c|c|c|c|c|c|c|c|c|c|c|c|}
\hline & $*$ & 0 & 1 & 2 & 3 & 4 & 5 & 6 & 7 & 8 & 9 \\
\hline r0 & 0 & 0 & 0 & 0 & 0 & 0 & 0 & 0 & 0 & 0 & 0 \\
\hline $\mathrm{r} 1$ & 1 & 0 & 1 & 2 & 3 & 4 & 5 & 6 & 7 & 8 & 9 \\
\hline r2 & 2 & 0 & 2 & 4 & 6 & 8 & 0 & 2 & 4 & 6 & 8 \\
\hline r3 & 3 & 0 & 3 & 6 & 9 & 2 & 5 & 8 & 1 & 4 & 7 \\
\hline $\mathrm{r} 4$ & 4 & 0 & 4 & 8 & 2 & 6 & 0 & 4 & 8 & 2 & 6 \\
\hline r5 & 5 & 0 & 5 & 0 & 5 & 0 & 5 & 0 & 5 & 0 & 5 \\
\hline r6 & 6 & 0 & 6 & 2 & 8 & 4 & 0 & 6 & 2 & 8 & 4 \\
\hline r7 & 7 & 0 & 7 & 4 & 1 & 8 & 5 & 2 & 9 & 6 & 3 \\
\hline r8 & 8 & 0 & 8 & 6 & 4 & 2 & 0 & 8 & 6 & 4 & 2 \\
\hline r9 & 9 & 0 & 9 & 8 & 7 & 6 & 5 & 4 & 3 & 2 & 1 \\
\hline
\end{tabular}

Table 18 showing the binary representation of multiplication on quotient ring $\mathrm{Z} / 10 \mathrm{Z}$

Table 18. Binary Representation of Z/10Z.

\begin{tabular}{|c|c|c|c|c|c|c|c|c|c|c|}
\hline r0 & 0 & 0 & 0 & 0 & 0 & 0 & 0 & 0 & 0 & 0 \\
\hline $\mathrm{r} 1$ & 0 & 1 & 0 & 1 & 0 & 1 & 0 & 1 & 0 & 1 \\
\hline r2 & 0 & 0 & 0 & 0 & 0 & 0 & 0 & 0 & 0 & 0 \\
\hline r3 & 0 & 1 & 0 & 1 & 0 & 1 & 0 & 1 & 0 & 1 \\
\hline $\mathrm{r} 4$ & 0 & 0 & 0 & 0 & 0 & 0 & 0 & 0 & 0 & 0 \\
\hline r5 & 0 & 1 & 0 & 1 & 0 & 1 & 0 & 1 & 0 & 1 \\
\hline r6 & 0 & 0 & 0 & 0 & 0 & 0 & 0 & 0 & 0 & 0 \\
\hline r7 & 0 & 1 & 0 & 1 & 0 & 1 & 0 & 1 & 0 & 1 \\
\hline r8 & 0 & 0 & 0 & 0 & 0 & 0 & 0 & 0 & 0 & 0 \\
\hline r9 & 0 & 1 & 0 & 1 & 0 & 1 & 0 & 1 & 0 & 1 \\
\hline
\end{tabular}

\section{Conclusions}

When studying the quotient rings $\mathrm{Z} / 15 \mathrm{Z}, \mathrm{Z} / 21 \mathrm{Z}, \mathrm{Z} / 35 \mathrm{Z}$, $\mathrm{Z} / 45 \mathrm{Z}$ and $\mathrm{Z} / 10 \mathrm{Z}$ and their binary representation we found the following results:

\subsection{For $n$ Is Odd, and $n \neq p^{m}$ Where $p$ Is Prime}

(1) In binary representation of $Z / n Z$, the length of each row is $n$, started by zero, each row with index relatively prime with $n$ has $(n+1) / 2$ of " $0 . \mathrm{s",}(n-1) / 2$ of " 1 .s", satisfy the first condition of orthogonal, the number of these rows is $\varphi(n)$, the first half of them is basic and the second half is their conjugates where the indexes computed $\bmod n$.

(2) If $i$ is prime then $\mathrm{R} i+\mathrm{R}(n-i)=\left[\begin{array}{lllll}0 & 1 & 1 & 1 & \ldots\end{array}\right]_{n}$ that is $R i=\overline{R(n-i)}$ except the first entry is zero in both of them

(3) In $\mathrm{Z} / 15 \mathrm{Z}$; the number of the biggest binary orthogonal closed sets (in the space $2^{15}$ ) which we can get them from $\mathrm{Z} / 15 \mathrm{Z}$ is at most $\left(\begin{array}{l}8 \\ 3\end{array}\right)=\left(\begin{array}{c}\varphi(10) \\ 3\end{array}\right)=\left(\begin{array}{c}\varphi(3) \varphi(5) \\ 3\end{array}\right)=56$ sets with; dimension 3 , length 15 , and size or capacity 7 and minimum distance 6 , of each set.

(4) In $\mathrm{Z} / 21 \mathrm{Z}$; the number of the biggest binary orthogonal closed sets (in the space $2^{21}$ ) which we can get them from $\mathrm{Z} / 21 \mathrm{Z}$ is at most $\left(\begin{array}{l}12 \\ 2\end{array}\right)=\left(\begin{array}{c}\varphi(12) \\ 2\end{array}\right)=\left(\begin{array}{c}\varphi(3) \varphi(7) \\ 2\end{array}\right)=66$ sets with; dimension 2 , length 21 , and size or capacity 3 , and minimum distance 10 , of each set while the expected dimensions and sizes for each of set are at least 4 and 17 respectively.

(5) In Z/35Z; the number of the biggest binary orthogonal closed sets (in the space $2^{35}$ ) which we can get them from $\mathrm{Z} / 35 \mathrm{Z}$ is at most $\left(\begin{array}{l}24 \\ 3\end{array}\right)=\left(\begin{array}{c}\varphi(35) \\ 3\end{array}\right)=\left(\begin{array}{c}\varphi(5) \varphi(7) \\ 3\end{array}\right)=2024$ sets with; dimension 3 , length 35 , and size or capacity 7 , and minimum distance 17, of each set, while the expected dimensions and sizes for each of set are at least 5 and 31 respectively.

(6) In $\mathrm{Z} / 45 \mathrm{Z}$; the number of the biggest binary orthogonal closed sets (in the space $2^{45}$ ) which we can get them from $\mathrm{Z} / 45 \mathrm{Z}$ is at most $\left(\begin{array}{l}24 \\ 3\end{array}\right)=\left(\begin{array}{c}\varphi(45) \\ 3\end{array}\right)=\left(\begin{array}{c}\varphi\left(3^{3}\right) \varphi(5) \\ 3\end{array}\right)=2024$ sets with; dimension 3 , length 35 , and size or capacity 7 , and minimum distance 22, of each set, while the expected dimensions and sizes for each of set are at least 5 and 31 respectively. 


\subsection{For $n$ Is Even}

(a) The number of the biggest binary orthogonal closed sets (in the space $2^{n}$ ) which we can get them from $\mathrm{Z} / n \mathrm{Z}$ is only $\mathrm{n} / 2$ sets with; dimension 1 , length $n$, and size or capacity 1 of each set, and this case is very trivial.

(b) From above in the quotient ring $\mathrm{Z} / n \mathrm{Z}$, and $n$ is odd, the dimension of orthogonal set is don't increase or increase very slaw with increasing $n$ and consequently their capacity but we can get orthogonal sets with biggest lengths and biggest minimum distances $(n-1) / 2$.

(c) The increase in the natural number does not necessarily lead to an increase in the size of the biggest orthogonal set in the corresponding quotient ring (see 3.1.1 and 3.1.2).

(d) In $\mathrm{Z} / n \mathrm{Z}$ the length any sequence in orthogonal set is $\mathrm{n}$ and the minimum distance is between $(n-3) / 2$ and $(n-1) / 2$.

Limitation: This method of compose sequences is useful for only binary sequences and the addition on the sequences computed by " $\bmod 2$ " also used Microsoft Word 2010 and the Microsoft equation 3.0 for written the math equations.

The method for reading a page which has a block will be according to the following direction as in figure 1 .

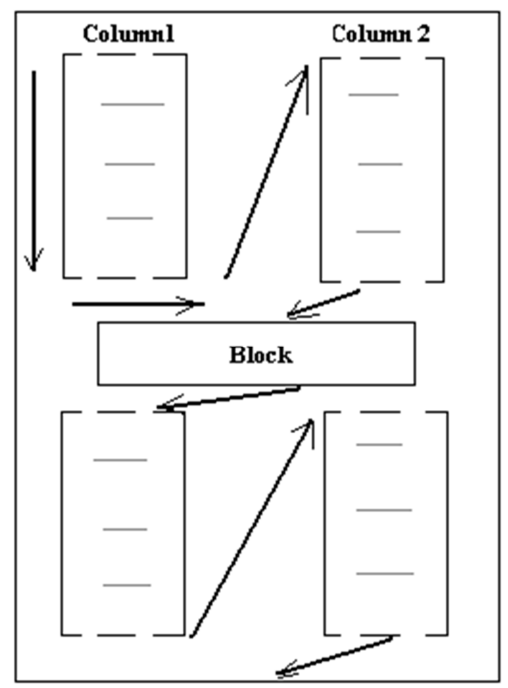

Figure 1. How reading pages with two columns and horizontal block.

\section{Acknowledgements}

The author express their gratitude to Prof. Abdulla Y Al Hawaj, President of Ahlia University for all the support.

\section{References}

[1] Sakrison D. J., (1968), Communication Theory: Transmission of Waveforms and Digital information, Publisher: John Wiley \& Sons Inc.
[2] Al Cheikha A. H. (July, 2017). Compose M-Sequences. Australian Journal of Business, Social Science and Information Technology. AJBSSIT. Vol. 3, Issue 3. Pp. 119126.

[3] Al Cheikha A. H. (2017). Compose Binary Matrices. American Journal of Computer sciences and Applications. AJCSA. Vol. 1, Issue 2. Pp. 0001-0017.

[4] Al Cheikha A. H. (September, 2014). Some Properties of MSequences Over Finite Field Fp. International Journal of Computer Engineering \& Technology. IJCER. Vol. 5, Issue 9. Pp. 61-72.

[5] Al Cheikha A. H. (September, 2014). Composed Walsh Sequences and M-Sequences. International Journal of Computers \& Technology. IJCT. Vol. 15, Issue 7. Pp. 69336939.

[6] Al Cheikha A. H. (2017). Composed Reed Solomon Sequences Generated by $i^{\text {th }}$ Partial Sum of Geometrical Sequences. American Journal of Computer sciences and Applications. AJCSA. Vol. 1, Issue 1. Pp. 0001-000116.

[7] Byrnes, J. S.; Swick. (1970), "Instant Walsh Functions”, SIAM Review., Vol. 12, pp. 131.

[8] David, J., "Introductory Modern Algebra," Clark University, USA, 2008.

[9] Jong-Seon No, Solomon W. \& Golomb, (1998), "Binary Pseudorandom Sequences For period $2^{\mathrm{n}}-1$ with Ideal Autocorrelation. IEEE Trans. Information Theory", Vol. 44 No 2, PP 814-817.

[10] Lee J. S \& Miller L. E, (1998), “CDMA System Engineering Hand Book”, Artech House. Boston, London.

[11] Lidl, R. \& Pilz, G., (1984), "Applied Abstract Algebra", Springer-Verlage New York.

[12] Lidl, R. \& Nidereiter, H., (1994), "Introduction to Finite Fields and Their Application", Cambridge University USA.

[13] Al Cheikha A. H. (2018). Generating New Binary Sequences Using Quotient Rings $\mathrm{Z} / p^{m} \mathrm{Z}$, Research Journal of Mathematics and Computer Science, RJMCS, ISSN: 25763989, Vol. 2 Issue 11. Pp. 1-13.

[14] Mac Williams, F. G \& Sloane, N. G. A., (2006), "The Theory of Error-Correcting Codes", North-Holland, Amsterdam.

[15] Sloane, N. J. A., (1976), "An Analysis Of The Stricture and Complexity Of Nonlinear Binary Sequence Generators, IEEE Trans. Information Theory" Vol. It 22 No 6, PP 732-736.

[16] Thomson W. Judson, (2013), “Abstract Algebra: Theory and Applications", Free Software Foundation.

[17] Yang S. C, (1998), "CDMA RF System Engineering”, ArtechHouse. Boston-London. 